\title{
PROGESTERONE SECRETION FROM THE OVARY IN THE EWE FOLLOWING INFUSION OF UTERINE VENOUS PLASMA
}

\author{
D. T. BAIRD, * R. A. COLLETT, ${ }^{*}$ I. S. FRASER,* \\ R. W. KELLY, $\uparrow$ R. B. LAND $\ddagger$ AND A. G. WHEELER $\ddagger$ \\ *Department of Obstetrics and Gynaecology, University of Edinburgh, \\ $\dagger$ M.R.C. Clinical Endocrine Unit, and $\ddagger$ A.R.C. Animal Breeding \\ Research Organization, Edinburgh
}

(Received 29th August 1972)

\begin{abstract}
Summary. The luteolytic activity of uterine venous plasma collected from donor ewes at different stages of the oestrous cycle was tested by observing the change in the rate of progesterone secretion from the CL of recipient ewes with the ovary autotransplanted to the neck. The mean percentage depression of rate of progesterone secretion was $9.6 \%$ in four experiments when plasma was infused from ewes on Days 9,10 or 11 of the cycle compared to $33.0 \%$ during seven experiments with plasma from Days 14,15 or 16 . The mean PGF $_{2 \alpha}$ concentration $(1.38 \mathrm{ng} / \mathrm{ml})$ as measured by combined gas chromatography/mass spectrometry in uterine venous plasma collected around the time of luteal regression was greater than that in plasma collected on Days 9,10 or $11(0.47 \mathrm{ng} / \mathrm{ml})$. These findings confirm the increase in luteolytic activity of uterine venous plasma collected at the time of expected luteal regression.
\end{abstract}

\section{INTRODUGTION}

In sheep, as in pigs, guinea-pigs and cows, the uterus appears to influence luteal regression (for review, see Anderson, Bland \& Melampy, 1969). It has been suggested that the uterus releases a luteolytic substance at the time of luteal regression which reaches the adjacent ovary (Short, 1967). The nature of this substance and the pathway whereby it reaches the ovary are still unknown although preliminary evidence suggests that prostaglandin $F_{2 \alpha}$ $\left(\mathrm{PGF}_{2 \alpha}\right)$, released from the uterus, may reach the CL by a counter-current mechanism (Barrett \& co-authors, 1971; McCracken, Baird \& Goding, 1971). Division of all structures between the ovary and the uterus results in maintenance of the CL (Inskeep \& Butcher, 1966); and ligation of the uterine vein and artery, but not of the artery alone, inhibits luteal regression (Kiracofe, Menzies, Gier \& Spies, 1966). Normal cyclical ovarian activity is preserved, however, if the uterine vein is left intact, suggesting that a luteolytic substance is transported from the uterus through the uterine vein (Baird \& Land, 1973).

The isolation and identification of potential luteolytic substances from the 
uterus have been hampered by the lack of a suitable experimental system in which to test their activity (Caldwell, Rowson, Moor \& Hay, 1969). When the ovary of the ewe is autotransplanted to the neck, luteal regression fails to occur because of the absence of an adjacent uterine horn (Goding, McCracken \& Baird, 1967; Baird, Goding, Ichikawa \& McCracken, 1968). This preparation has been used successfully for demonstrating the luteolytic activity of PGF $_{2 \alpha}$ when infused through the ovarian artery (McCracken, Glew \& Scaramuzzi, 1970; Barrett et al., 1971). Preliminary experiments suggest that uterine venous blood collected at the time of luteal regression may contain luteolytic activity (Caldwell \& Moor, 1971; McCracken et al., 1971).

This paper describes the effects on progesterone secretion of the infusion of uterine venous blood and plasma, collected from donor ewes at different stages of the oestrous cycle, into the ovarian artery of recipient ewes with ovarian autotransplants.

\section{MATERIALS AND METHODS}

The experimental design was similar, although not identical, in all twelve experiments. Uterine venous blood, collected at operation from donor ewes at known stages of the oestrous cycle, was infused through the autotransplanted ovary of recipient ewes via the ovarian artery.

\section{Collection of uterine venous blood from donor ewes}

Details of the stage of oestrous cycle of the donor ewes and identity of the recipient ewes are given in Table 1 . Oestrus was identified both pre- and postoperatively by teasing with a vasectomized ram at least once a day. Two heats were usually recorded before collection, the dioestrous interval ranging from 15 to 18 days (mean \pm S.E. $=16 \cdot 4 \pm 0 \cdot 2, n=16$ ).

On the morning of experiment, the uterus was exposed through a mid-line ventral incision under Nembutal-induced halothane anaesthesia. A $75-\mathrm{cm}$ nylon catheter (o.d. $2 \cdot 1 \mathrm{~mm}$, No. B205, Portex Ltd, Hythe, Kent) was inserted into the uterine vein on one side through one of the main branches. It was secured in position by two No. 0 silk sutures with the tip lying 1 to $2 \mathrm{~cm}$ above the junction of the middle uterine vein and the ovarian vein. The catheter was threaded through a stab incision in the ventral abdominal wall and the free end was allowed to hang over the end of the table. Heparin (5000 i.u.) was given intravenously and uterine venous blood was allowed to drip into a sterile collection vessel on ice. During collection, an equivalent volume of plasma expander (Dextraven 70 'Macrodex', Pharmacia) was infused through the jugular vein. Uterine vein blood ( 400 to $600 \mathrm{ml}$ ) was collected from each animal, the time of collection varying between 95 and 140 min $($ mean \pm S.E. $=$ $115 \pm 7 \mathrm{~min}$ ). In eight of the experiments, the samples of uterine venous blood were centrifuged at $2000 \mathrm{rev} / \mathrm{min}$ at $4^{\circ} \mathrm{C}$ for $30 \mathrm{~min}$ immediately after collection and the plasma was aspirated. The uterus was lightly attached to the ventral abdominal wall with a No. 1 silk suture, care being taken not to enter the uterine lumen. After closing the abdominal incision with two layers of mersilk sutures, the ewe was allowed to recover from the anaesthetic. The catheter was 


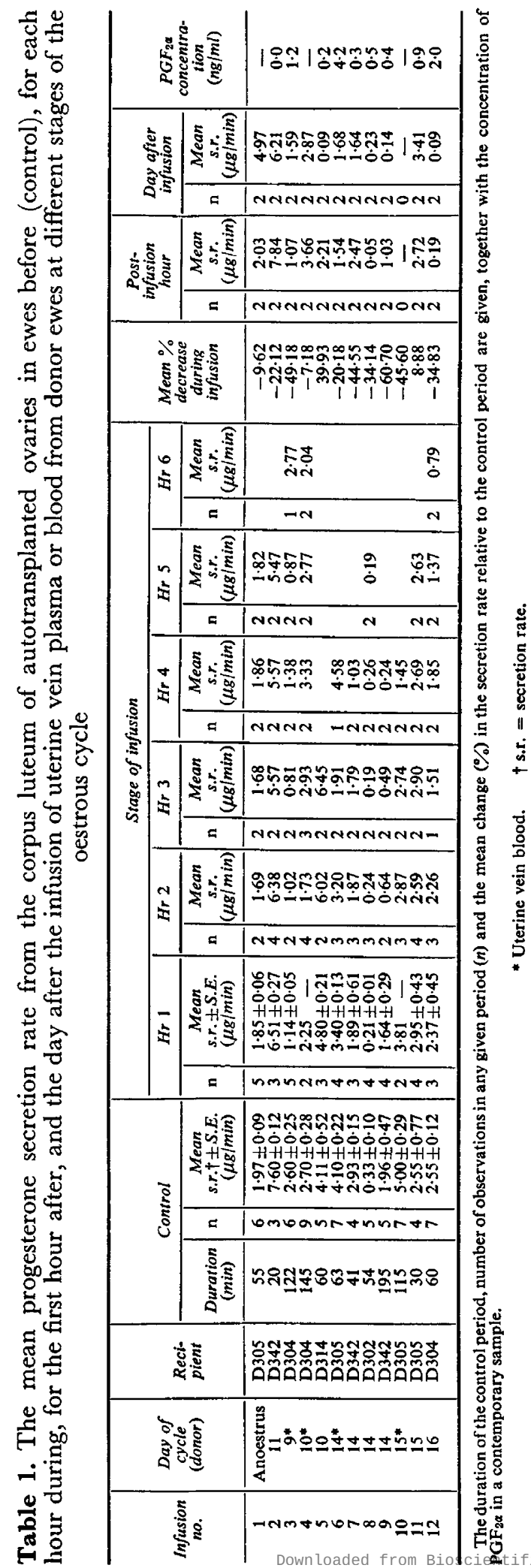


filled with a weak heparin solution (10 i.u./ml saline), closed and attached to the wool of the back.

After the operation, the donor ewes were tested for oestrus once a day and daily samples of uterine venous blood were collected as long as the catheter remained patent.

\section{Recipient ewes}

Five Tasmanian Merino ewes, with the left ovary autotransplanted to a carotid-jugular skin loop in the neck (Goding et al., 1967) were used as recipient ewes. The ovary of all these ewes contained at least one CL (as indicated by a progesterone secretion rate greater than $0.5 \mu \mathrm{g} / \mathrm{min}$ during the collection on the day before the experiment) which had been maintained because of the physical separation of uterus and ovary (Baird et al., 1968). Samples of ovarian venous blood were collected during the 3 days before the experiment and the ewes were tested daily for oestrus with a vasectomized ram.

On the morning of the experiment, the carotid artery and jugular vein in the skin loop were cannulated as well as the contralateral jugular vein (Goding, et al., 1967; Collett, Land \& Baird, 1973). After the cannulation, the recipient ewes were placed in metabolism cages under minimal restraint for at least $2 \mathrm{hr}$ before any collections were made. At time 0 (between 12.00 and 13.00 hours), an infusion of saline was started through the ovarian artery by means of a constant infusion pump at the rate of $0.6 \mathrm{ml} / \mathrm{min}$ (Collett et al., 1973). Four to six timed samples of ovarian venous blood were collected and then the saline infusion was replaced by an infusion of uterine venous blood or plasma from the donor ewe $(0.6$ to $1.3 \mathrm{ml} / \mathrm{min})$ approximately $1 \mathrm{hr}$ later. Further samples of ovarian venous blood were collected from the recipient ewes throughout the duration of the infusion ( 4 to $5 \mathrm{hr}$ ) and then at intervals for up to $48 \mathrm{hr}$. The ewes were tested for oestrus twice daily for at least 3 days after the infusion.

\section{Secretion rate of progesterone and oestradiol $-17 \beta$}

The progesterone concentration in samples of ovarian venous plasma was measured using a competitive protein-binding technique (Collett et al., 1973) and the progesterone secretion rate was calculated from a knowledge of the haematocrit and the ovarian blood flow. In Exp. 12, the concentration of oestradiol- $17 \beta$ in selected samples of uterine venous plasma was measured, using a double isotope derivative method (Baird, 1968).

\section{Prostaglandin measurement}

In nine of the twelve experiments, $100 \mathrm{ml}$ uterine venous blood were collected from recipient ewes at the beginning of the experiment for measurement of the concentration of $\mathrm{PGF}_{2 \alpha}$. Some $40,000 \mathrm{~d} / \mathrm{min}$ of $\left[{ }^{3} \mathrm{H}-9\right] \mathrm{PGF}_{2 \alpha}(10.7 \mathrm{Ci} /$ mmol) (New England Nuclear Chemicals, Postfadr 71, Germany) purified before use by thin-layer chromatography (see later), were added to the collection tube to correct for procedural losses. The plasma was separated by centrifugation at $5^{\circ} \mathrm{C}$ and stored at $-20^{\circ} \mathrm{C}$ until analysis.

The $\mathrm{pH}$ of the plasma was adjusted to 9 by adding $1 \mathrm{~N}-\mathrm{NaOH}$ and the plasma was extracted once with an equal volume of diethylether. The ether extract 
was discarded and $1 \mathrm{~N}-\mathrm{HCl}$ was added drop by drop to give a final value of $\mathrm{pH}$ 3. The acidified plasma was extracted three times with an equal volume of diethylether. The combined ether extracts were washed with $1 / 10$ vol. of water to neutrality and dried under nitrogen. The residue was then redissolved in $10 \mathrm{ml}$ of $66 \%$ aqueous ethanol and partitioned three times with an equal volume of petroleum ether (b.p. 40 to $60^{\circ} \mathrm{C}$ ) which had been previously saturated with $66 \%$ ethanol. The $66 \%$ ethanol, containing the prostaglandins, was evaporated under nitrogen and the aqueous residue was acidified to $\mathrm{pH} 3$, and extracted three times with an equal volume of ether. The combined ether fractions were washed to neutrality with water and evaporated to dryness.

The residue was applied to the origin of a thin-layer plate $(0.50 \mathrm{~mm}$ Silica gel-G-Merck) using 95\% acetone. The plates were developed in benzene: dioxane: acetic acid (50:50:1), and the $\mathrm{PGF}_{2 \alpha}$ spots were identified by running standards in parallel lanes, and eluting from the silica gel using $10 \mathrm{ml}$ of $95 \%$ acetone. The dried residue was redissolved in $2 \mathrm{ml}$ water, acidified to $\mathrm{pH} 3$, and extracted three times with $5 \mathrm{ml}$ diethylether. The combined ether extracts were washed three times with $1 / 10 \mathrm{vol}$. of water and then evaporated under nitrogen. The mean recovery was estimated at this point $(57 \pm 3 \%)$ by counting a $1 / 25$ aliquot in a liquid scintillation counter and the remainder was used for estimating the mass of endogenous $\mathrm{PGF}_{2 \alpha}$.

Prostaglandin $\mathrm{F}_{2 \alpha}$ levels were measured by combined gas chromatographymass spectrometry, using PGF $_{1 \alpha}$ as internal standard. The absence of endogenous $\mathrm{PGF}_{1 \alpha}$ was determined before analysis. Both $\mathrm{PGF}_{2 \alpha}$ and the internal standard were measured by gas chromatography as the methyl ester-9,11-butyl boronate-15-trimethylsilyl ether.

Aliquots of extract were evaporated at the bottom of $2 \times 70-\mathrm{mm}$ tubes and $20 \mathrm{ng} \mathrm{PGF}_{1 \alpha}$ were added, followed by $25 \mu \mathrm{l}$ diazomethane solution in ether. After $10 \mathrm{~min}$, the diazomethane solution was evaporated and $30 \mu \mathrm{l}$ of a $2 \%$ solution of butyl boronic acid in acetone benzene ( $4: 1)$ were added. The tube was placed in a vacuum oven at $60^{\circ} \mathrm{C}$ and under a pressure of $400 \mathrm{~mm} \mathrm{Hg}$. After $20 \mathrm{~min}$, the pressure was reduced to evaporate the solution to dryness. A $25-\mu \mathrm{l}$ vol. of bis (trimethylsilyl trifluoroacetamide) was added and the contents of the tube were analysed $2 \mathrm{hr}$ later. The mass spectra of the triple derivatives of both $\mathrm{PGF}_{2 \alpha}$ and $\mathrm{PGF}_{1 \alpha}$ show prominent ions due to loss of the pentyl chain $\left(\mathrm{C}_{16}-\mathrm{C}_{20}\right)$ at mass/charge $(\mathrm{m} / \mathrm{e}) 435$ and $\mathrm{m} / \mathrm{e} 437$, respectively. These $\mathrm{m} / \mathrm{e}$ values were continuously monitored during the gas chromatography and the ratio of the heights of the $\mathrm{PGF}_{2 \alpha}$ peak over the height of the $\mathrm{PGF}_{1 \alpha}$ peak was used for quantification (Kelly, 1972). The separation of $\mathrm{PGF}_{2 \alpha}$ and $\mathrm{PGF}_{1 \alpha}$ peaks by the combination of gas chromatography and mass spectrometry was such that zero contribution from the PGF $_{1 \alpha}$ was recorded in the PGF ${ }_{2 \alpha}$ channel. The analyses were performed with a Pye 106 chromatograph coupled through a Watson Biemann separator to an A.E.I. MS12 mass spectrometer.

\section{RESULTS}

The effects of the infusion of uterine vein plasma on the autotransplanted ovary were assessed in two ways; firstly, as the progesterone secretion rate before, 
during, and after the infusion of the plasma and secondly, in terms of the change in the secretion rate of progesterone during the infusion of plasma. The details of the results of each infusion are summarized in Table 1, where the absolute progesterone secretion rates are given for the control period and for each hour of the infusion, together with the first hour after infusion and the day after infusion when these had been measured. The mean percentage decreases in secretion rate are represented in Text-fig. 1 for the infusion of jugular venous plasma, the four experiments with Day-9, -10 or -11 plasma (Day 10), and the seven experiments when uterine venous plasma was collected towards the end of the oestrous cycle on Days 14, 15 or 16 (Day 15). In contrast to jugular

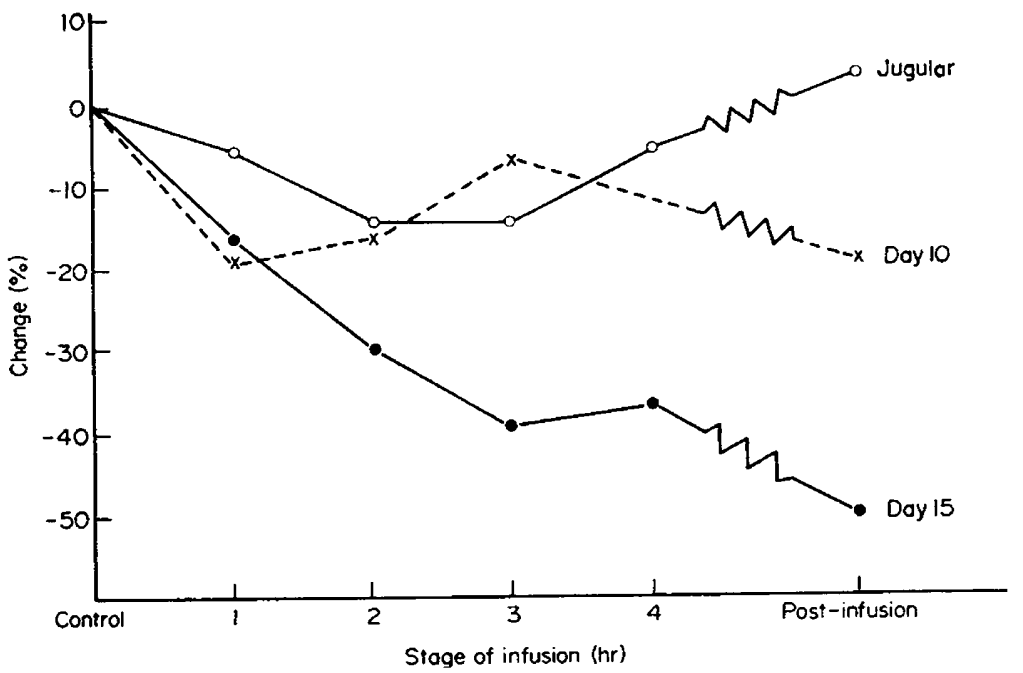

Text-pIG. 1 . The change $(\%)$ in the mean hourly secretion rate of progesterone by the autotransplanted ovary of the ewe during the infusion of jugular venous plasma, or of uterine vein plasma collected around Day 10 or Day 15 of the oestrous cycle.

venous plasma (Exp. 1), infusion of uterine venous plasma from both groups resulted in a $20 \%$ decline in progesterone secretion during the first hour. As time progressed, however, the reduction in the secretion rate in the Day- 10 group fluctuated around $15 \%$ whereas, in the Day-15 group, the mean secretion rate declined progressively to less than $50 \%$ of the control values (Text-fig. 1 and Table 1).

When the mean secretion rate throughout the course of infusion was compared to that of the control period by the use of a $t$ test, it was found that it was reduced significantly in eight of the total of twelve infusions $(P<0.05)$, remained unchanged in three experiments, and increased on only one occasion. In terms of the two stages of the oestrous cycle, plasma collected around Day 10 led to one increase and two decreases in the secretion rate, the fourth infusion leaving it unchanged; the mean hourly percentage decrease in the secretion rate was $9 \cdot 6 \%$. Plasma collected around Day 15 was associated with a decrease in progesterone secretion in five of the seven experiments; the mean percentage hourly decrease in secretion rate was $33.0 \%$. 
The results were analysed in terms of the change in the secretion rate of progesterone during the course of the infusion of uterine venous plasma. The progesterone secretion rate declined significantly during the course of the infusion of some of the samples collected towards the end of the oestrous cycle, the regression coefficient of secretion rate on time being negative $(P<0.05)$ in three of the seven infusions. The only other statistically significant change

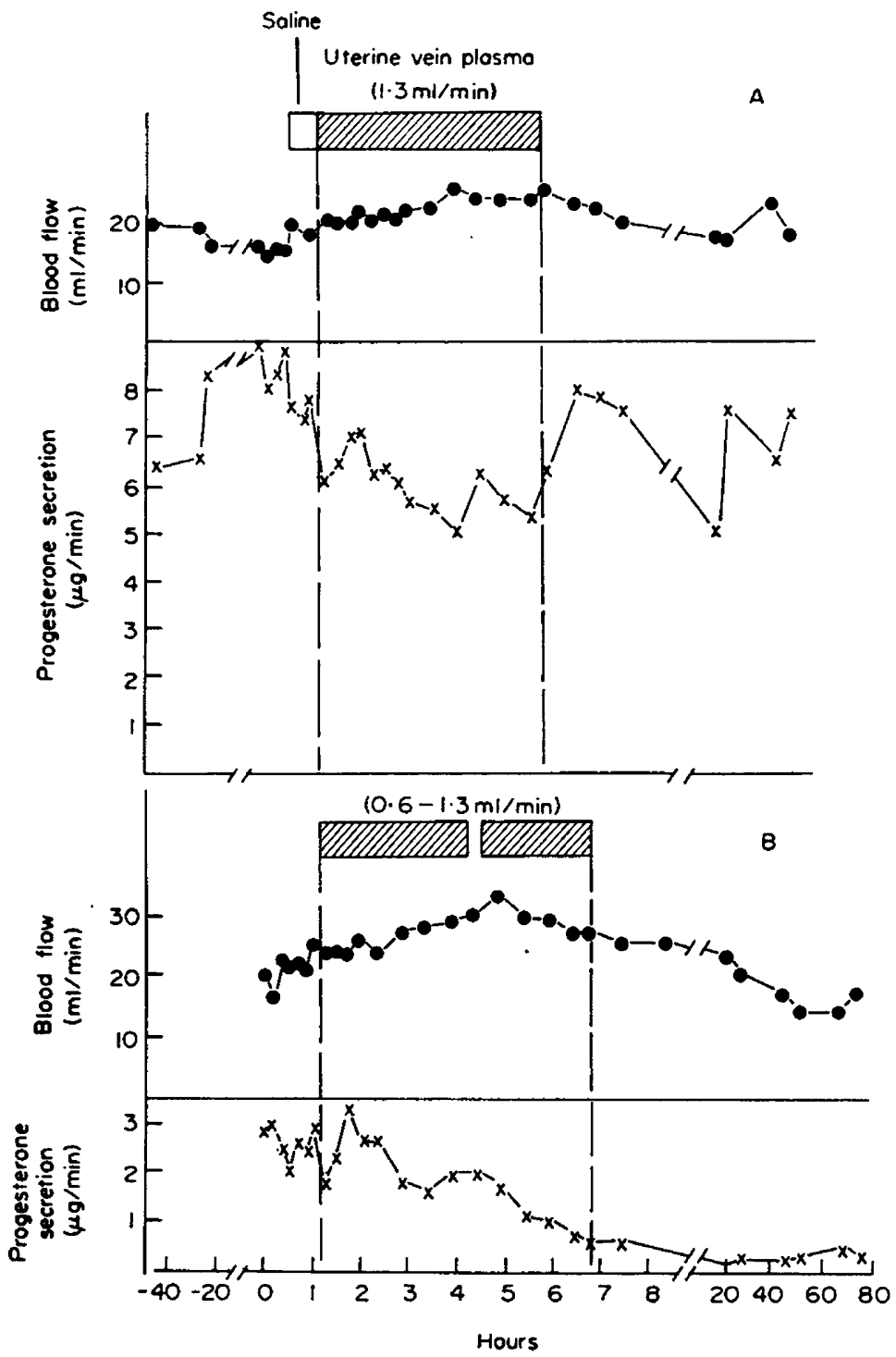

TEXT-FIG. 2. Secretion rate of progesterone ( $\mu \mathrm{g} / \mathrm{min})$ and ovarian blood flow $(\mathrm{ml} / \mathrm{min})$ from the autotransplanted ovary in Exps 2 and 12. Infusion through the ovarian artery of uterine venous plasma collected from a donor ewe on Day 16 of the cycle resulted in a marked depression in the secretion rate of progesterone $(B)$ in contrast to the effect of plasma obtained from the same donor ewe on Day 11 (A). 
observed during the twelve infusions was an increase during one of the Day-10 experiments.

In one donor ewe, the catheter remained patent for a sufficient length of time to allow plasma to be collected on Day 11 (Exp. 2) and again on Day 16 (Exp. 12). The results of these two experiments are illustrated in Text-fig. 2. Infusion of plasma for $5 \mathrm{hr}$ on Day 11 resulted in a temporary fall in progesterone secretion in the recipient ewe, whereas virtual cessation of progesterone secretion occurred after the infusion of uterine venous plasma collected from the same donor 7 days later. There was a significant decline in secretion rate during this latter infusion $(b=-0.00544 \pm 0.00098 \mu \mathrm{g} / \mathrm{min} / \mathrm{min})$. In spite of the depression of progesterone secretion, the ewe failed to return to oestrus and the secretion rate of oestradiol-17 $\beta$ remained low throughout the experiment (less than $1 \mathrm{ng} / \mathrm{min}$ ).

The individual PGF $_{2 \alpha}$ concentrations are also given in Table 1 for the experiments when they were measured. Although the range of values was high, the mean $\mathrm{PGF}_{2 \alpha}$ concentration at the end of the cycle $(1.38 \mathrm{ng} / \mathrm{ml})$ was approximately three times greater than that around Day $10(0.47 \mathrm{ng} / \mathrm{ml})$. The correlation between individual infusion values was only $0 \cdot 1$, indicating that the two were not associated within experiments.

In nine of the twelve experiments, the donor ewe was tested for oestrus after operation. Three of these failed to return to oestrus within 18 days of the previous oestrus and in each case, at least one CL had been present in the ovary on the side on which the uterine vein was cannulated. In five of the remaining six ewes which returned to oestrus when expected (cycle length $=16 \cdot 8 \pm 0.3$ days), the ovary on the side cannulated was free of CL. In the sixth ewe, the ovary which contained a CL on the side of the cannulation was removed at the operation. The cannulation of the middle uterine vein appeared therefore to delay the regression of $\mathrm{CL}$ on the ipsilateral ovary.

\section{DISCUSSION}

The present experiments confirm that uterine venous plasma collected around the time of luteal regression is capable of causing depression of progesterone secretion from the CL (Caldwell \& Moor, 1971). The mean luteolytic activity of uterine venous plasma from the Day-15 group was much greater than that from the Day-10 group. In Exp. 3 on Day 9, however, a significant decline in progesterone secretion occurred, suggesting that the presence of a luteolytic factor in uterine venous blood is not confined exclusively to the time of luteal regression.

The levels of $\mathrm{PGF}_{2 \alpha}$ in uterine venous plasma reported in this paper are in the same range as the levels previously published (Bland, Horton \& Poyser, 1971; McCracken et al., 1971; Thorburn, Cox, Currie, Restall \& Schneider, 1972). The mean concentration of $\mathrm{PGF}_{2 \alpha}$ was higher in the Day-15 group than in the Day-10 group, although there was considerable variation in the values. The lack of correlation between the concentration of $\mathrm{PGF}_{2 \alpha}$ in uterine venous plasma and luteolytic activity in individual experiments could be explained by the intermittent nature of the release of $\mathrm{PGF}_{2 \alpha}$ from the uterus (Thorburn 
et al., 1972). Thus, the $\mathrm{PGF}_{2 \alpha}$ concentration in a contemporary sample of uterine venous plasma obtained at the beginning of the period of collection may not have been representative of the mean value in the plasma tested for luteolytic activity.

None of the ewes returned to oestrus within $48 \mathrm{hr}$ of stopping the infusion although in three experiments (5, 9 and 12), the secretion rate of progesterone was depressed by over $90 \%$. The relatively low levels of $\mathrm{PGF}_{2 \alpha}$ (maximum $\mathbf{4 \cdot 2}$ $\mathrm{ng} / \mathrm{ml}$ ) and short periods of infusion (maximum $6 \mathrm{hr}$ ) were probably insufficient to induce complete luteal regression. When $\mathrm{PGF}_{2 \alpha}$ is infused directly into the ovarian artery, a minimum rate of 1 to $2 \mu \mathrm{g} / \mathrm{hr}$ is required to ensure that regression of the CL and subsequent oestrus occurs (Goding, Baird, Cumming \& McCracken, 1971).

When the CL was on the ovary contralateral to the cannulation, oestrous cycles of normal length were recorded post-operatively, indicating that the operative procedure per se did not upset ovarian function. The failure to exhibit oestrus in all three ewes in which the ovary on the side of cannulation contained at least one CL, however, suggests that in these animals luteal regression was inhibited. Dobrowolski, Stupnicka \& Domanski (1968) noted that two of six cows in which a chronic catheter had been placed in the uterine vein failed to return to oestrus at the expected time. The vascular connections between the uterus and ovary appear to be essential for normal luteal regression (Kiracofe $e t$ al., 1966) and selective ligation of the uterine vein results in luteal maintenance (Baird \& Land, 1973). These experiments, therefore, support the view that the middle uterine vein plays an essential rôle in luteal regression (Baird \& Land, 1973).

\section{ACKNOWLEDGMENTS}

The authors are grateful for the technical assistance of Miss Marjorie Fordyce and Mr R. D. Preece, Mr G. Davidson and Mr A. D. Macgregor. This work was supported in part by a Grant from the Medical Research Council.

\section{REFERENCES}

Anderson, L. L., Bland, K. P. \& Melampy, R. M. (1969) Comparative aspects of uterine-luteal relationships. Recent Prog. Horm. Res. 25, 57.

BAIRD, D. T. (1968) A double isotope derivative method for the estimation of oestrone and oestradiol$17 \beta$ in peripheral human blood, ovarian and adrenal venous blood of sheep and other biological fluids using $\left[{ }^{35}\right.$ S $]$ pipsyl chloride. F. clin. Endocr. Metab. 28, 244.

Baird, D. T., Goding, J. R., Ichikawa, Y. \& McCracken, J. A. (1968) The secretion of steroids from the autotransplanted ovary in the ewe spontaneously and in response to systemic gonadotrophin. 7. Endocr. 42, 283.

BAIRD, D. T. \& LAND, R. B. (1973) Division of the uterine vein and the function of the adjacent ovary in the ewe. 7. Reprod. Fert. 33, 393.

Barrett, S., Blockey, M. A. de B., Brown, J. M., Cumming, I. A., Goding, J. R., Mole, B. J. \& OBst, J. M. (1971) Initiation of the oestrous cycle in the ewe by infusions of PGF $_{2 \alpha}$ to the autotransplanted ovary. F. Reprod. Fert. 24, 136 (Abstr.).

Bland, K. P., Horton, E. W. \& Poyser, N. L. (1971) Levels of prostaglandin $F_{2 \alpha}$ in the uterine venous blood of sheep during the oestrous cycle. Life Sciences, 10, 509.

Caldwelz, B. V. \& Moor, R. M. (1971) Further studies on the rôle of the uterus in the regulation of corpus luteum function in sheep. F. Reprod. Fert. 26, 133.

Caldwell, B. V., Rowson, L. E. A., Moor, R. M. \& HAY, M. F. (1969) The utero-ovarian relationship and its possible role in infertility. F. Reprod. Fert. Suppl. 8, 59. 
Collett, R. A., LAND, R. B. \& Baird, D. T. (1973) The pattern of progesterone secretion by the autotransplanted ovary of the ewe in response to ovine luteinizing hormone. 7. Endocr. $56,403$.

Dobrowolski, W., Stupnicka, E. \& Domaśski, E. (1968) Progesterone levels in ovarian venous blood during the oestrous cycle of the cow. J. Reprod. Fert. 15, 409.

Goding, J. R., Baird, D. T., Cumming, I. A. \& MaCracken, J. A. (1971) Functional assessment of autotransplanted endocrine organs. In: Perfusion Techniques, 4th Karolinska Symposium on Research Methods in Reproductive Endocrinology, p. 169. Ed. E. Diczfalusy. Karolinska Institutet, Stockholm. Also published as Suppl. 158 to Acta endocr., Copenh.

Goding, J. R., McGracken, J. A. \& BAIRd, D. T. (1967) The study of ovarian function in the ewe by means of a vascular autotransplantation technique. 7 . Endocr. 39, 37.

INSKeEp, E. K. \& ButcheR, R. L. (1966) Local component of utero-ovarian relationships in the ewe. 7. Anim. Sci. 25, 1164.

KELLY, R. W. (1972) Quantitative measurement of prostaglandin by gas chromatography-mass spectrometry. In: Proc. Int. Symp. on Gas Chromatography-Mass Spectrometry, p. 19. Ed. A. Frigerio. Tamburini Editore, Milan.

Kiracofe, G. H., Menzies, C. S., Gier, H. T. \& Spies, H. G. (1966) Effect of uterine extracts and uterine or ovarian blood vessel ligation on ovarian function of ewes. 7. Anim. Sci. 25, 1159.

McCracken, J. A., Baird, D. T. \& Goding, J. R. (1971) Factors affecting the secretion of steroids from the transplanted ovary in the sheep. Recent. Prog. Horm. Res. 27, 537.

MaCracken, J. A., Glew, M. E. \& Scaramuzzi, R. J. (1970) Corpus luteum regression induced by prostaglandin $\mathrm{F}_{2 \alpha}$. 7. clin. Endocr. Metab. 30, 544 .

Short, R. V. (1967) Reproduction. A. Rev. Physiol. 29, 373.

Thorburn, G. D., Cox, R. I., Currie, W. B., Restall, B. J. \& Schneider, W. (1972) Prostaglandin F concentration in the utero-ovarian venous plasma of the ewe during the oestrous cycle. $\mathcal{F}$. Endocr. 53, 325. 